\title{
An upper limit for macromolecular crowding effects
}

Andrew C Miklos ${ }^{1}$, Conggang Li ${ }^{1,2}$, Courtney D Sorrell ${ }^{3,4,5}, \mathrm{~L}$ Andrew Lyon ${ }^{3,4}$ and Gary J Pielak $k^{1,6,7^{*}}$

\begin{abstract}
Background: Solutions containing high macromolecule concentrations are predicted to affect a number of protein properties compared to those properties in dilute solution. In cells, these macromolecular crowders have a large range of sizes and can occupy $30 \%$ or more of the available volume. We chose to study the stability and ps-ns internal dynamics of a globular protein whose radius is $\sim 2 \mathrm{~nm}$ when crowded by a synthetic microgel composed of poly(N-isopropylacrylamide-co-acrylic acid) with particle radii of $\sim 300 \mathrm{~nm}$.

Results: Our studies revealed no change in protein rotational or ps-ns backbone dynamics and only mild $\left(\sim 0.5 \mathrm{kcal} / \mathrm{mol}\right.$ at $\left.37^{\circ} \mathrm{C}, \mathrm{pH} 5.4\right)$ stabilization at a volume occupancy of $70 \%$, which approaches the occupancy of closely packing spheres. The lack of change in rotational dynamics indicates the absence of strong crowder-protein interactions.

Conclusions: Our observations are explained by the large size discrepancy between the protein and crowders and by the internal structure of the microgels, which provide interstitial spaces and internal pores where the protein can exist in a dilute solution-like environment. In summary, microgels that interact weakly with proteins do not strongly influence protein dynamics or stability because these large microgels constitute an upper size limit on crowding effects.
\end{abstract}

\section{Background}

The cellular interior, where most biological processes occur, is unlike the dilute solutions where most proteins are studied. The large volume excluded by high macromolecule concentrations in cells, from $20-40 \%$ [1], is predicted to change many protein properties compared to dilute solution. We used a synthetic microgel composed of poly ( $N$-isopropylacrylamide-co-acrylic acid) [ $p$-NIPAm-co-AAc (Figure 1A)], as a crowding agent to study the backbone dynamics and the stability of the globular test protein, chymotrypsin inhibitor 2 (CI2).

$p$-NIPAm-co-AAc is of interest in pharmaceutical applications because it forms environmentally sensitive microgels [2]. Each microgel particle (Figure 1B) is a lightly cross-linked single polymer molecule of molecular weight $10^{9} \mathrm{Da}$ with an average of 70 monomer units between each cross link. The polymer absorbs a large amount of water resulting in spherical particles of

\footnotetext{
* Correspondence: gary_pielak@unc.edu

'Department of Chemistry, University of North Carolina, Chapel Hill, North Carolina 27599, USA

Full list of author information is available at the end of the article
}

$300 \mathrm{~nm}$ radii that exclude large amounts of solution volume. Their porosity arises from the balance between the external (solution) osmotic pressure and the internal osmotic pressure. This internal pressure is the result of the solvated cations that neutralize the deprotonated polymer side chains. We chose this crowding agent because its status as a drug delivery molecule makes it pharmaceutically relevant, and its ability to take up water provides a model for volume exclusion by a molecule much larger than our test protein.

CI2 is a small globular protein $(7.4 \mathrm{kDa}, \mathrm{PDB}$ ID: $2 \mathrm{CI} 2)$ that exhibits two-state folding [3]. NMR relaxation experiments [4] allowed us to assess backbone rotational dynamics for $\mathrm{CI} 2$ in the presence and absence of $p$-NIPAm-co-AAc. Amide proton exchange experiments $[5,6]$ allowed us to assess the stability of CI2 in dilute and crowded conditions.

Globular proteins are often treated like hard spheres, but they have measurable amounts of internal motion. Analysis of relaxation parameters from NMR experiments - longitudinal and transverse relaxation times, $T_{1}$ and $T_{2}$, and the ${ }^{15} \mathrm{~N}-{ }^{1} \mathrm{H}$ nuclear Overhauser effect 

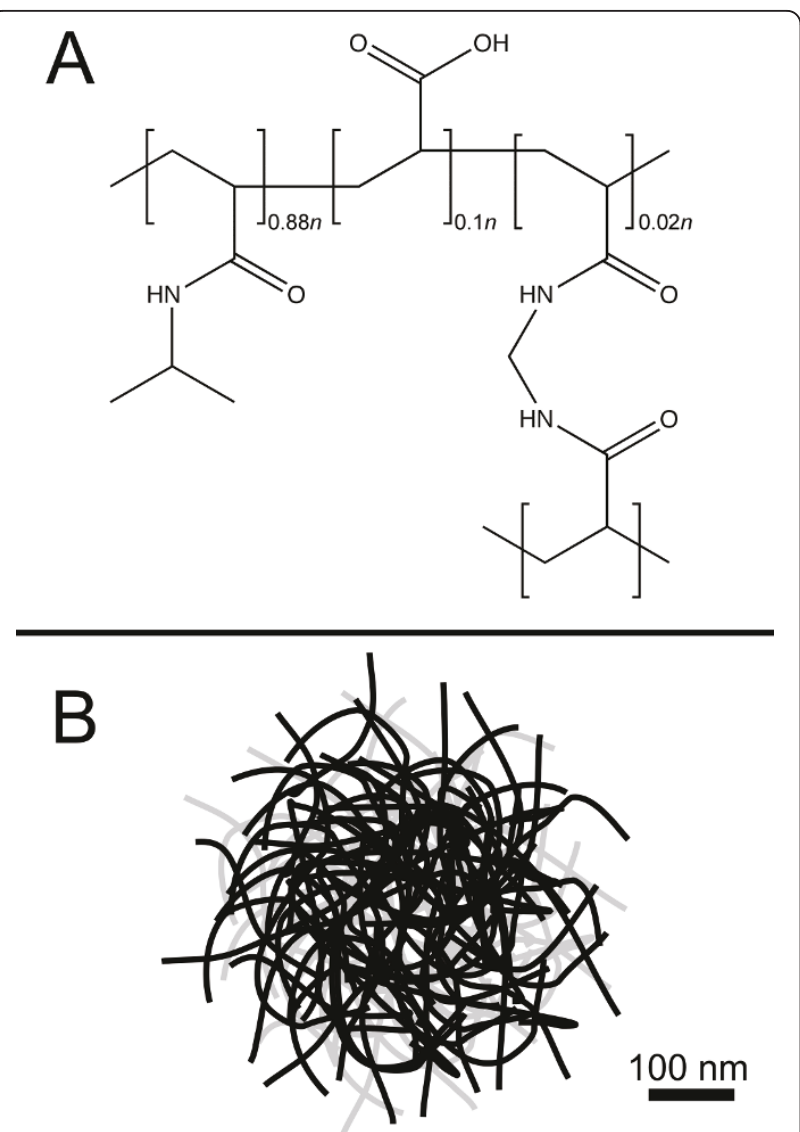

Figure 1 Structure and Size of $p$-NIPAm-co-AAc: A) The monomeric repeat of NIPAm. B) Overall shape and size of $p$-NIPAmco-AAc microgels.

(NOE) of backbone ${ }^{15} \mathrm{~N}$ atoms - offers a residue-level window into this ps-ns backbone motion. The analysis involves a model-free method established by Lipari and Szabo [7]. Analysis is performed by fitting the spectral density function $I(\omega)$ as calculated from measured $T_{1}$, $T_{2}$, and NOE values [8], to the equation [7]

$$
I(\omega)=\frac{2}{5}\left[\frac{S^{2} \tau_{m}}{1+\omega^{2} \tau_{m}^{2}}+\frac{\left(1-S^{2}\right) \tau}{1+\omega^{2} \tau^{2}}\right]
$$

The overall correlation time $\tau$ is linked to the correlation time for isotropic tumbling, $\tau_{m}$, and internal motion timescale, $\tau_{e}$, by the equation

$$
\frac{1}{\tau}=\frac{1}{\tau_{e}}+\frac{1}{\tau_{m}}
$$

with the internal motions faster than the overall isotropic tumbling. The order parameter, $S^{2}$, can have values between 0 and 1 , and is related to the degree of internal mobility for a particular ${ }^{1} \mathrm{H}_{-}{ }^{15} \mathrm{~N}$ vector. An $S^{2}$ value of 0 corresponds to complete freedom of motion. In this instance, relaxation is related solely to internal motion. An $S^{2}$ value of 1 corresponds to complete restriction of the vector with respect to overall molecule motion, and relaxation is related solely to isotropic tumbling of the protein. These parameters can be linked to models for motion, in our case, the "wobble-in-a-cone" model [7]. Variations of Lipari-Szabo analysis exist for cases involving ms timescale conformational exchange, but no CI2 residue (except Thr40) has significant contributions from slow exchange [9]. It is also possible to study the equilibrium thermodynamic stability of globular proteins by using NMR.

Amide proton exchange experiments can be used with NMR to assess protein stability. The technique relies on the exchange of amide protons for deuterons in a $\mathrm{D}_{2} \mathrm{O}$ solution. We have recently reviewed the requirements for its application in crowded solution by using NMR [10].

Exchange occurs via the scheme

$$
c l-{ }^{1} H \underset{k_{c l}}{\stackrel{k_{o p}}{\longrightarrow}} o p-{ }^{1} H \stackrel{k_{\text {int }}}{\longrightarrow} o p-{ }^{2} H \quad \text { (Scheme 1) }
$$

with opening rate $k_{o p}$, closing rate $k_{c l}$, and rate of exchange from the open state $k_{\text {int }}$. If the protein is stable $\left(k_{c l}>>k_{o p}\right)$ and exchange from the open state is rate limiting, the stability of an amide proton against exchange $\left(\Delta G_{o p}^{0 *}\right)$ can be determined with the equation,

$$
\Delta G_{o p}^{0 *}=-R T \ln \frac{k_{o b s}}{k_{\text {int }}}
$$

where $R$ is the gas constant and $T$ is the absolute temperature. The value of $k_{o b s}$, the overall rate of exchange for any particular backbone amide proton, is assessed by acquiring ${ }^{1} \mathrm{H}_{-}{ }^{15} \mathrm{~N}$ heteronuclear single quantum correlation (HSQC) spectra as a function of time after initiating exchange. As with dynamics, $\Delta G_{o p}^{0 *}$ can be quantified on a per-residue basis. The largest $\Delta G_{o p}^{0 *}$ values match the global protein stability values determined by other methods (e.g., calorimetry, circular dichroism spectropolarimetry) [11].

\section{Results}

Experiments were performed by using samples comprising $1 \mathrm{mM} \mathrm{CI} 2$ in $50 \mathrm{mM}$ sodium acetate solution, $\mathrm{pH}$ 5.4 at $37^{\circ} \mathrm{C}$. Crowded samples also contained $10 \mathrm{~g} / \mathrm{L}$ $p$-NIPAm-co-AAc microgels.

\section{Polymer Characterization}

The microgels composed of $p$-NIPAm-co-AAc have an average hydrodynamic radius $\left(R_{H}\right)$ of $312 \mathrm{~nm}$ and an average polydispersity of $7.4 \%$. The molecular weight of the microgels was estimated to be $1 \mathrm{GDa}$ by multiple angle laser light scattering [12]. 


\section{Controls for Amide Proton Exchange}

To determine whether exchange from the open state $\left(k_{\text {int }}\right)$ is rate limiting, nuclear Overhauser enchancement spectroscopy-detected amide proton exchange (NOESYHEX) experiments were performed [10]. The results are given in Table 1, along with individual backbone residue decay rates from HSQC-detected amide proton exchange.

To determine whether $k_{\text {int }}$ values are changed by crowding, phase-modulated clean exchange (CLEANEX$\mathrm{PM}$ ) experiments [13] were used to determine $k_{\text {int }}$ for residues on the extended loop region of CI2. For His37, $k_{\text {int }}$ values were $11 \pm 2 \mathrm{~s}^{-1}$ in dilute solution and $8 \pm 2 \mathrm{~s}^{-1}$ in $10 \mathrm{~g} / \mathrm{L} p$-NIPAm-co-AAc.

\section{Dynamics}

Analysis of the $T_{1}, T_{2}$, and NOE data (Additional File 1) acquired in dilute solution and in $10 \mathrm{~g} / \mathrm{L} p$-NIPAm-coAAc yielded the values for $\tau_{\mathrm{m}}, S^{2}$, and $\tau_{\mathrm{e}}$. The value of $\tau_{\mathrm{m}}$ was the same ( $4.1 \mathrm{~ns})$ in dilute solution and in $10 \mathrm{~g} / \mathrm{L}$ $p$-NIPAm-co-AAc, and is consistent with the value obtained by Shaw et al. in dilute solution [9]. Histograms of $S^{2}$ and $\tau_{\mathrm{e}}$ versus residue number are shown in Figure 2. Linear least squares analysis of a plot of $S^{2}$ in dilute solution versus $S^{2}$ in crowded solution gives a slope of $1.0 \pm$ 0.1 , a y-intercept of $0.1 \pm 0.1$ and an $R^{2}$ value of 0.80 .

\section{Amide Proton Exchange and Stability}

Values for $k_{o b s}$ were determined in triplicate for solutions in the presence and absence of $10 \mathrm{~g} / \mathrm{L} p$-NIPAm-co-AAc. Exchange was slowed in $10 \mathrm{~g} / \mathrm{L} p$-NIPAm-co-AAc compared to dilute solution (Figure 3). Values of $\Delta G^{O^{*}}$ op were determined by using values for $k_{\text {int }}$ calculated from

\section{Table 1 NOESY-HEX results}

\begin{tabular}{|c|c|c|}
\hline Residue(s) & $k_{\text {obs }} \operatorname{NOESY~}\left(\mathrm{s}^{-1} \times 10^{5}\right)$ & $\mathrm{k}_{\mathrm{obs}} \mathrm{HSQC}\left(\mathrm{s}^{-1} \times 10^{5}\right)$ \\
\hline Leu8 & 3 & 3 \\
\hline Val9 & 2 & 2 \\
\hline Leu8 + Val9 ${ }^{a}$ & 5 & 5 \\
\hline Leu8, Val9 ${ }^{b}$ & 5 & N/A \\
\hline Lys17 & 52 & 40 \\
\hline Lys 18 & 20 & 15 \\
\hline Lys $17+\operatorname{Lys} 18^{a}$ & 72 & 55 \\
\hline Lys17, Lys18 & 50 & N/A \\
\hline Ala58 & 3 & 4 \\
\hline Glu59 & 3 & 3 \\
\hline Ala58 + Glu59 & 6 & 7 \\
\hline Ala58, Glu59 b & 7 & N/A \\
\hline
\end{tabular}

$k_{a b s}$ values from NOESY-detected amide proton exchange and HSQC-detected amide proton exchange for $\mathrm{Cl} 2$ in $10 \mathrm{~g} / \mathrm{L} p$-NIPAm-Co-AAC, $50 \mathrm{mM}$ sodium acetate, $\mathrm{pH} 5.4,37^{\circ} \mathrm{C}$.

a Sum of values from individual crosspeak decays.

${ }^{\mathrm{b}}$ Exchange rate of amide-amide NOESY crosspeak.
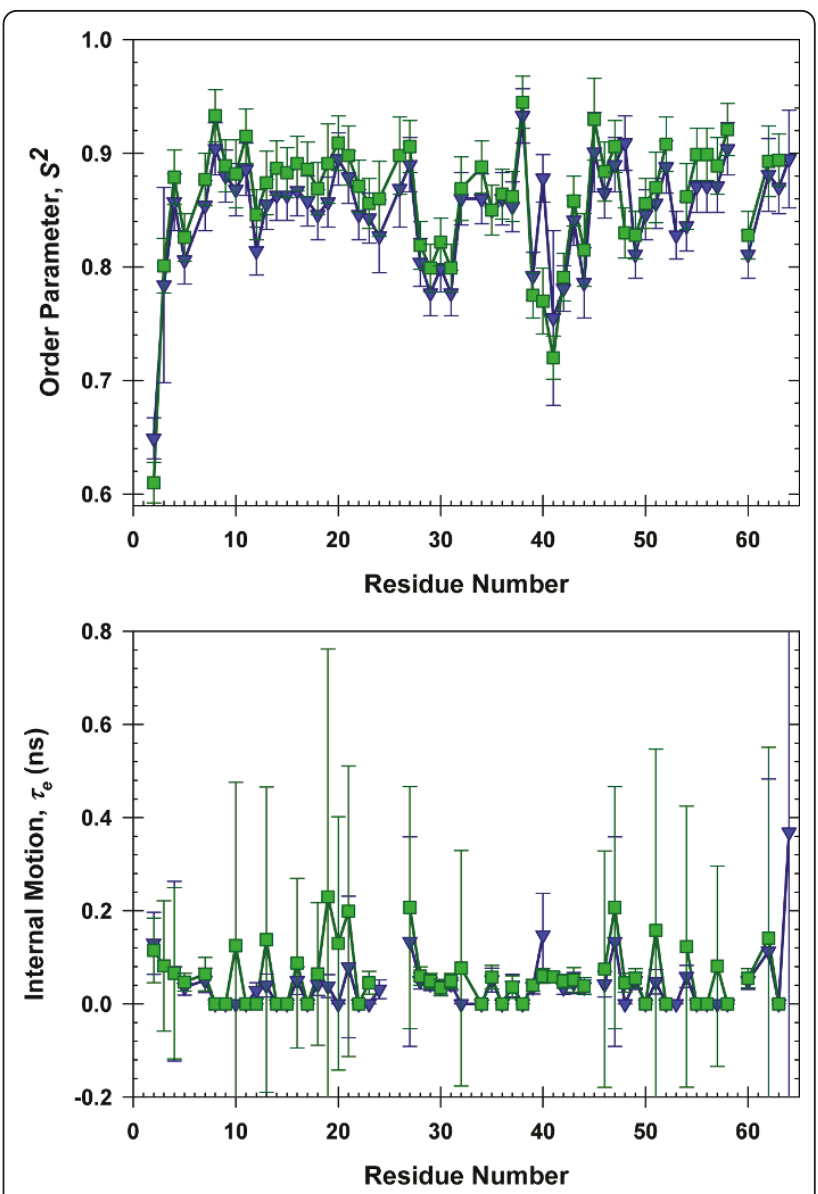

Figure $2 \mathrm{Cl} 2$ dynamics in $\boldsymbol{p}$-NIPAm-co-AAc: Order parameters (upper panel) and timescales of internal motion (lower panel) for $\mathrm{Cl} 2$ in dilute solution and in $10 \mathrm{~g} / \mathrm{L}$ NIPAm-AAC.

SPHERE [14] and $k_{o b s}$ values from amide proton exchange experiments. A listing of values is given in Additional File 2. A histogram of $\Delta G^{O^{*}}{ }_{\text {op }}$ versus residue number is shown in Figure 4.

\section{Discussion}

The volume occupancy of $p$-NIPAm-co-AAc solutions defines the degree of crowding. Using a hydrodynamic radius of $312 \mathrm{~nm}$ and a molecular weight of $1 \mathrm{GDa}$, the microgel in a $10 \mathrm{~g} / \mathrm{L}$ solution occupies $\sim 70 \%$ of the solution volume at $\mathrm{pH} 5.4$ and $37^{\circ} \mathrm{C}$ (the conditions used in our experiments). The practical limit of spherical packing is $64 \%$ volume occupancy [15], but soft materials such as microgels can be "overpacked" [16]. Our solutions, however, were still in the liquid state, meaning our value for volume occupancy is likely an overestimate. The high value does, however, suggest that experimental conditions were within the realm of crowding, as other systems show crowding effects at less than $20 \%$ volume occupancy $[17,18]$.

Although the microgel slowed exchange (Figure 3), it was necessary to perform control experiments to ensure 


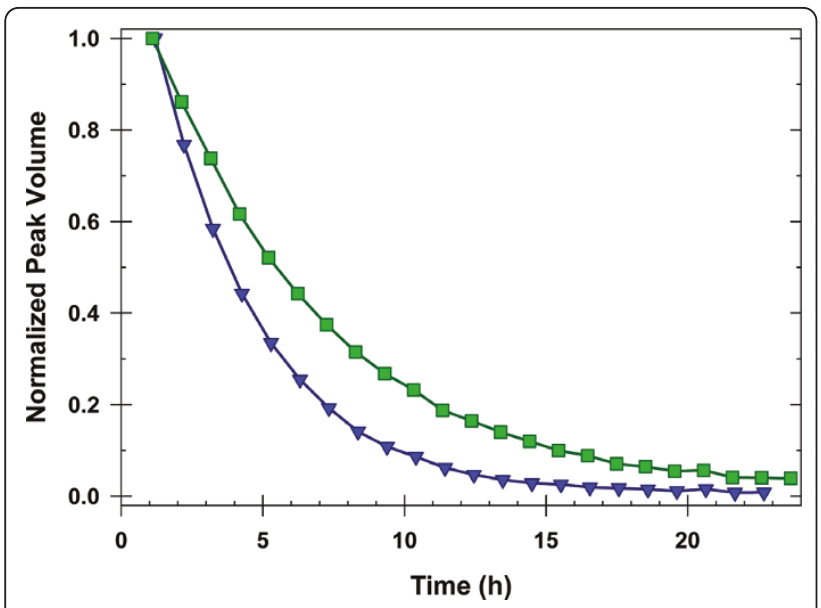

Figure 3 Exchange Curves: Amide proton exchange curves for Lys24 in dilute solution (blue triangles) and in $10 \mathrm{~g} / \mathrm{L} \mathrm{p-NIPAm-co-}$ AAc (green squares). Values for $k_{o b s}$ are $7.53 \pm 0.05 \times 10^{-5} \pm \mathrm{s}^{-1}$ in dilute solution and $4.55 \pm 0.05 \times 10^{-5} \mathrm{~s}^{-1}$ in $10 \mathrm{~g} / \mathrm{L}$-NIPAm-CO-AAc. These uncertainties are from non-linear least squares fitting and are smaller than the uncertainty from triplicate analysis.

that stability values could be obtained under both sets of conditions. First, we confirmed that amide proton exchange from the open state $\left(k_{i n t}\right.$, Scheme 1$)$ is rate limiting. Under this condition, pairs of proximal amide protons, $\mathrm{A}$ and $\mathrm{B}$, open with the same frequency, but with different $k_{\text {int }}$ values. That is, amide proton exchanges for A and B are uncorrelated. By observing the decay of an amide-amide NOESY crosspeak corresponding to a resonance coupling between $\mathrm{A}$ and $\mathrm{B}$, it is possible to determine whether their exchange is correlated or uncorrelated. If the exchange is uncorrelated,

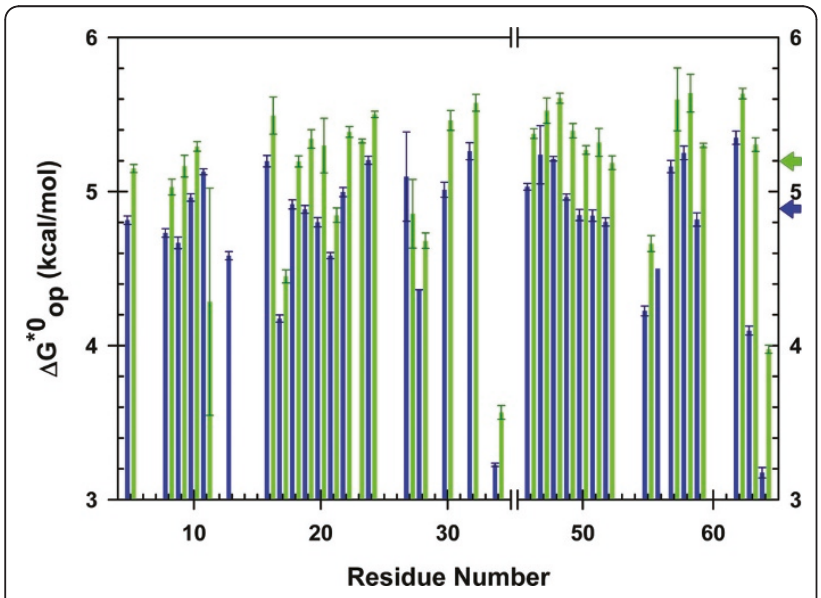

Figure $4 \mathrm{CI} 2$ stability in $p$-NIPAm-co-AAc: Results are shown for dilute solution (blue) and $10 \mathrm{~g} / \mathrm{L}$ p-NIPAm-co-AAc (green). Error bars reflect the standard error in $k_{\text {obs }}$ values from three trials. Colored arrows indicate the average $\Delta G^{O^{*}}$ op values for globally exchanging residues [20] in crowded $(5.2 \mathrm{kcal} / \mathrm{mol})$ and dilute $(4.9 \mathrm{kcal} / \mathrm{mol})$ solution. the decay curve of the amide-amide crosspeak should equal the product of the individual amide proton decay curves $[19,20]$,

$$
I_{A B}=I_{A} \cdot I_{B}
$$

In this instance, the overall exchange rate of the amide-amide crosspeak will correspond to the sum of the individual exchange rate constants,

$$
K_{A B}=K_{A}+K_{B}
$$

All these rates can be assessed from a series of ${ }^{15} \mathrm{~N}$-filtered ${ }^{1} \mathrm{H}-{ }^{1} \mathrm{H}$ NOESY spectra acquired under exchange conditions [10].

As shown in Table 1, the exchange rates observed for the amide-amide crosspeaks for $\mathrm{CI} 2$ in both dilute solution and in $10 \mathrm{~g} / \mathrm{L} p$-NIPAm-co-AAc are, within the uncertainty of the experiment, the sums of their respective individual exchange rates, indicating that the exchanges are uncorrelated. We conclude that exchange from the open state is rate limiting, allowing determination of stability from amide proton exchange rates.

Second, we must determine if the microgel changes $k_{\text {int }}$ from the values determined in dilute solution. The dilute solution value for each residue is calculated by using the computer program, SPHERE [14] (http://www. fccc.edu/research/labs/roder/sphere/). The program uses values from the exchange of free peptides [21], and relies solely on the primary structure of the test protein. We assessed whether $k_{\text {int }}$ is affected by adding $p$-NIPAm-co-AAc by using the CLEANEX-PM experiment [13]. We measured the exchange rate of the His37 amide proton, which is fully exposed in the flexible loop region of CI2 (residues 35-44). The data indicated that the intrinsic rate of exchange in $10 \mathrm{~g} / \mathrm{L} p$-NIPAm-coAAc $\left(8 \pm 2 \mathrm{~s}^{-1}\right)$ is within uncertainty of the value in dilute solution $\left(11 \pm 2 \mathrm{~s}^{-1}\right)$. These results suggest that $k_{\text {int }}$ values can be used without alteration. Having shown that it is valid to use $k_{o b s}$ and $k_{i n t}$ values to obtain opening free energies, we constructed histograms of $\Delta G^{O^{*}}{ }_{o p}$ values versus residue number (Figure 4).

\section{Dynamics and Stability}

Crowding involves two different types of effects on protein stability: volume exclusion and chemical interactions. Volume exclusion is expected to stabilize protein native states, whereas chemical interactions can be stabilizing or destabilizing [6]. Attractive chemical interactions are expected to impede rotational dynamics, and the microgel used here is known to have favorable electrostatic interactions with proteins at low ionic strength [22]. Our data were collected at pH 5.4, where the microgel is negatively charged. The truncated form of CI2 we use has an isoelectric point (pI) of 6 . Therefore, the polymer 
and $\mathrm{CI} 2$ are oppositely charged, and one might expect an attractive interaction.

Our observation that the order parameters $\left(S^{2}\right)$, the timescale of internal motion $\left(\tau_{e}\right)$, and the rotational correlation time $\left(\tau_{m}\right)$, are unchanged by the polymer indicates the absence of significant chemical interactions between the polymer and CI2. The lack of interaction probably arises because we used an ionic strength of 50 $\mathrm{mM}$, which minimizes binding [22]. Therefore, we only consider contributions from volume exclusion effects.

The patterns of $\Delta G^{O^{* \prime}}{ }_{o p}$ values along the amino acid sequence (Figure 4) are the same in dilute solution as they are in the microgel solution, suggesting that the microgel does not alter the open states of CI2. The $\Delta G^{O^{* *}}$ op values in the microgel are uniformly larger than the values for dilute solution, indicating the polymer stabilizes the protein with a maximal stability increase of approximately $0.4 \mathrm{kcal} / \mathrm{mol}$. Averaging the $\Delta G^{O^{*}}{ }_{o p}$ values from residues known to be implicated in global unfolding [20] show that the microgel increases the overall stability from $4.9 \mathrm{kcal} / \mathrm{mol}$ to $5.2 \mathrm{kcal} / \mathrm{mol}$. We cannot state with certainty that the increased stability arises from the polymeric nature of the microgel because its crosslinked nature makes determination of a suitable monomer unit difficult.

Considering the volume fraction estimate of $\sim 70 \%$, a 0.3 $\mathrm{kcal} / \mathrm{mol}$ stability increase is quite small. A modest increase is anticipated, however, because the hydrodynamic radius of CI2 is only $1 \%$ that of the $p$-NIPAm-co-AAc microgels (Figure 5). In such a system, CI2 can occupy interstitial spaces between $p$-NIPAm-co-AAc microgels, putting $\mathrm{CI} 2$ in a dilute solution environment. Alternatively, the microgel particles probably have pores large enough to accommodate $\mathrm{CI} 2$ and water.

Next, we try to relate the stability change to the backbone dynamics data (Figure 2). The data indicate that the increased stability does not alter the ps-ns backbone dynamics. It has been proposed that stability changes are associated with alterations of ps-ns backbone dynamics $[23,24]$. Our results do not indicate a connection, because we observe increased stability without a change in ps-ns timescale dynamics. The most straightforward conclusion is that stability is not linked to backbone ps-ns dynamics. It is possible, however, that stability is reflected in slower (ms-s) motions [25].

\section{Conclusions}

Even though the $10 \mathrm{~g} / \mathrm{L}$ solution of $p$-NIPAm-co-AAc microgels occupy $\sim 70 \%$ of solution volume, these conditions do not affect the ps-ns timescale backbone dynamics of CI2. The microgel, however, does have a modest stabilizing effect on the protein. These conclusions are explained by the fact that the majority of the protein occupies a water-like environment in interstitial

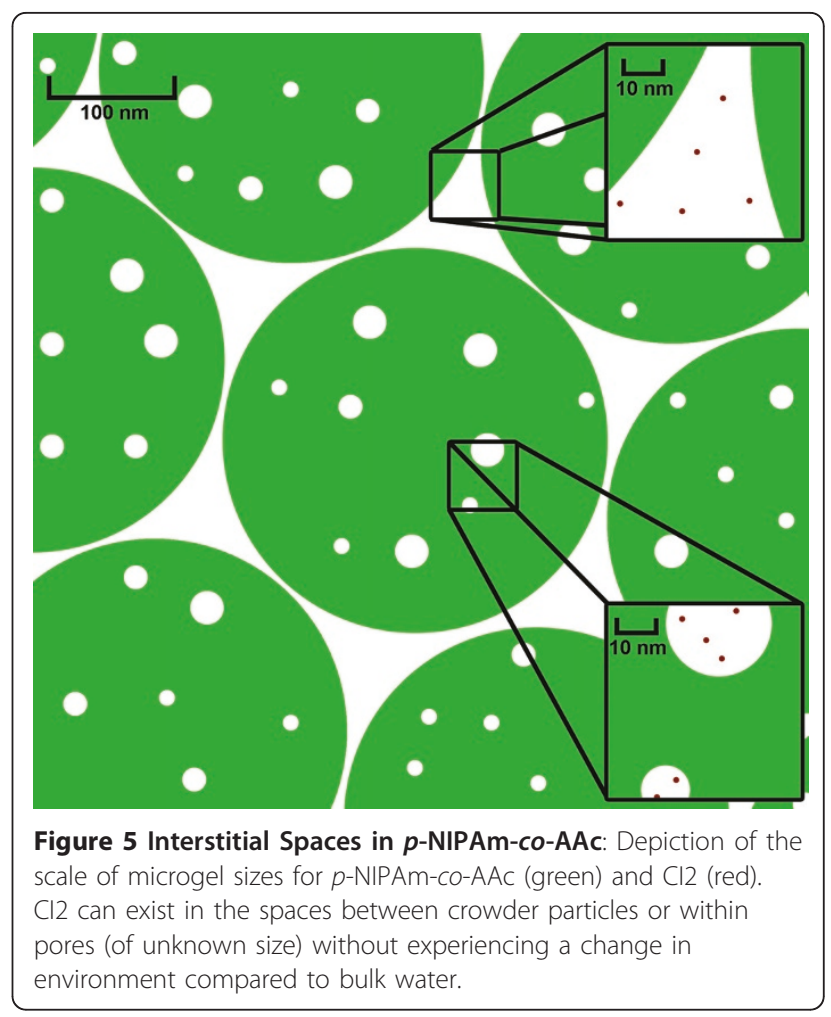

spaces of the microgel particles. In the context of $p$-NIPAm-co-AAc as a drug delivery tool, this is promising information, supporting the notion that these microgels are biocompatible materials. It seems likely, however, that larger crowding agents such as $p$-NIPAm-co-AAc can have more noticeable effects when present in mixed solutions that also contain multiple sizes of crowders [26].

\section{Methods}

${ }^{15} \mathrm{~N}$-enriched CI2 was expressed and purified as described by Miklos et al. [10].

\section{Polymer Synthesis and Characterization}

A general synthesis for NIPAm-AAc microgels is described by Jones and Lyon [27], but variations yield products with different properties (size, temperature, $\mathrm{pH}$ dependence, etc.) [28-30]. The microgels used here were prepared via aqueous, surfactant-free, free radical precipitation polymerization using $70 \mathrm{mM}$ total monomer concentration. Briefly, $\mathrm{N}$-isopropylacrylamide $(0.6973 \mathrm{~g})$ and $N, N$ '-methylenebis(acrylamide) ( $0.0215 \mathrm{~g}$ ) were dissolved in $99 \mathrm{~mL}$ of $\mathrm{H} 2 \mathrm{O}$ and filtered through a $0.8 \mu \mathrm{m}$ syringe filter into a round bottom flask. The mixture was bubbled with $\mathrm{N}_{2}(\mathrm{~g})$ and heated to $70^{\circ} \mathrm{C}\left( \pm 2^{\circ} \mathrm{C}\right)$ over $\sim 1 \mathrm{~h}$. Acrylic acid $(46 \mu \mathrm{L})$ was then added. Polymerization was initiated by adding a solution of $\left(\mathrm{NH}_{4}\right)_{2} \mathrm{~S}_{2} \mathrm{O}_{8}$ $(0.0226 \mathrm{~g})$ dissolved in $1 \mathrm{~mL}$ of $\mathrm{H}_{2} \mathrm{O}$. This reaction was stirred at $70^{\circ} \mathrm{C}\left( \pm 2^{\circ} \mathrm{C}\right)$ under a blanket of $\mathrm{N}_{2}(\mathrm{~g})$ for $4 \mathrm{~h}$ 
and was stirred and cooled overnight. The mixture was filtered through Whatman \#2 paper and stored. Aliquots of the resultant colloidal dispersion were purified with centrifugation at $15,000 \times \mathrm{g}$, decanted, and resuspended in $\mathrm{H}_{2} \mathrm{O}$. This process was performed three times. The particles were then lyophilized to yield a white powder.

The microgels were characterized after suspension in sodium acetate ( $\mathrm{pH} 5.4$ ) and passage through a $0.8 \mu \mathrm{m}$ filter. This solution was sonicated for $5 \mathrm{~min}$, allowed to equilibrate for $30 \mathrm{~min}$, then analyzed by using multiangle laser light scattering (MALLS) [12].

\section{NMR}

HSQC-detected and NOESY-HEX experiments were performed on a $500 \mathrm{MHz}$ Varian Inova spectrometer equipped with a triple-resonance $\mathrm{HCN}$ cold probe as described by Miklos et al. [10]. CLEANEX-PM experiments were conducted as described by Hwang et al. [13] with a $600 \mathrm{MHz}$ Varian Inova spectrometer equipped with a triple-resonance $\mathrm{HCN}$ probe with three-axis gradients system.

${ }^{15} \mathrm{~N} T_{1}$ and $T_{2}$ relaxation times and ${ }^{15} \mathrm{~N}\left\{{ }^{1} \mathrm{H}\right\}$ NOEs were measured as described by Kay et al. [31]. Experiments were performed on the $600 \mathrm{MHz}$ spectrometer. Lipari-Szabo model free analysis [7] was performed with the software package Relaxn 2.2. [32]. The majority of residues were fit with the original model-free formalism [4] to yield $\tau_{\mathrm{m}}, S^{2}$ and $\tau_{\mathrm{e}}$.

\section{Additional material}

Additional file $1:{ }^{15} \mathrm{~N} T_{1},{ }^{15} \mathrm{~N} T_{2}$, and ${ }^{1} \mathrm{H}^{15} \mathrm{~N}$ NOEs for $\mathrm{Cl} 2$. A table containing ${ }^{15} \mathrm{~N} \mathrm{~T}_{1},{ }^{15} \mathrm{~N} \mathrm{~T}_{2}$, and ${ }^{1} \mathrm{H}^{15}{ }^{15} \mathrm{NOE}$ values for $\mathrm{Cl} 2$ in dilute solution and $10 \mathrm{~g} / \mathrm{L}$ p-NIPAm-CO-AAC at $37^{\circ} \mathrm{C}, \mathrm{pH} 5.4$.

Additional file 2: $\mathrm{Cl} 2$ Stability Values. A table containing $\triangle G^{O^{*}}$ op values and standard error from triplicate results for $\mathrm{Cl} 2$ in $10 \mathrm{~g} / \mathrm{L} p$-NIPAm-CO$\mathrm{AAC}$ at $37^{\circ} \mathrm{C}, \mathrm{pH} 5.4$.

\begin{abstract}
Acknowledgements
This work was supported by the National Institutes of Health (5DP1OD783) and the National Science Foundation (MCB-1051819). We thank Gregory B. Young for spectrometer assistance and Elizabeth Pielak for helpful comments on the manuscript.
\end{abstract}

\footnotetext{
Author details

'Department of Chemistry, University of North Carolina, Chapel Hill, North Carolina 27599, USA. ${ }^{2}$ State Key Laboratory of Magnetic Resonance and Molecular and Atomic Physics, Wuhan Institute of Physics and Mathematics, Chinese Academy of Sciences, Wuhan, 430071, PR China. ${ }^{3}$ School of Chemistry \& Biochemistry, Georgia Institute of Technology, Atlanta, GA 30332, USA. ${ }^{4}$ Petit Institute for Bioengineering and Bioscience, Georgia Institute of Technology, Atlanta, GA 30332, USA. ${ }^{5}$ Department of Chemistry, University of Alberta, Edmonton, AB, T6G 2G2, Canada. ${ }^{6}$ Department of Biochemistry and Biophysics, University of North Carolina, Chapel Hill, North Carolina 27599, USA. ${ }^{7}$ Lineberger Comprehensive Cancer Center, University of North Carolina, Chapel Hill, North Carolina 27599, USA
}

\section{Authors' contributions}

$A C M, C L, L A L$, and GJP designed the research; $A C M$ and $C L$ performed the NMR experiments; CDS prepared and characterized microgels; ACM and GJP wrote the manuscript; All authors read and approved the final manuscript.

Received: 15 December 2010 Accepted: 31 May 2011

Published: 31 May 2011

\section{References}

1. Zimmerman SB, Trach SO: Estimation of macromolecule concentrations and excluded volume effects for the cytoplasm of Escherichia coli. J Mol Biol 1991, 222(3):599-620.

2. Pelton R: Temperature-sensitive aqueous microgels. Adv Colloid Interface Sci 2000, 85(1):1-33.

3. Jackson SE, Fersht AR: Folding of chymotrypsin inhibitor 2. 1. Evidence for a two-state transition. Biochemistry 2002, 30(43):10428-10435.

4. Jarymowycz VA, Stone MJ: Fast time scale dynamics of protein backbones: NMR relaxation methods, applications, and functional consequences. Chemical Reviews 2006, 106(5):1624-1671.

5. Charlton LM, Barnes CO, Li C, Orans J, Young GB, Pielak GJ: Macromolecular crowding effects on protein stability at the residue level. J Am Chem Soc 2008, 130:6826-6830.

6. Miklos AC, Li CG, Sharaf NG, Pielak GJ: Volume exclusion and soft interaction effects on protein stability under crowded conditions. Biochemistry 2010, 49(33):6984-6991.

7. Lipari G, Szabo A: Model-free approach to the interpretation of nuclear magnetic-resonance relaxation in macromolecules. 1. Theory and range of validity. J Am Chem Soc 1982, 104(17):4546-4559.

8. Palmer AG: NMR probes of molecular dynamics: Overview and comparison with other techniques. Annu Rev Biophys Biomol Struct 2001, 30:129-155.

9. Shaw GL, Davis B, Keeler J, Fersht AR: Backbone dynamics of chymotrypsin inhibitor 2: Effect of breaking the active-site bond and its implications for the mechanism of inhibition of serine proteases. Biochemistry 1995, 34(7):2225-2233.

10. Miklos AC, Li C, Pielak GJ: Using NMR-detected backbone amide ${ }^{1} \mathrm{H}$ exchange to assess macromolecular crowding effects on globularprotein stability. Methods Enzymol 2009, 466:1-18.

11. Huyghues-Despointes BMP, Scholtz JM, Pace CN: Protein conformational stabilities can be determined from hydrogen exchange rates. Nat Struct Biol 1999, 6(10):910-912.

12. Sorrell CD, Lyon LA: Deformation controlled assembly of binary microgel thin films. Langmuir 2008, 24(14):7216-7222

13. Hwang $T L$, van Zijl PCM, Mori S: Accurate quantitation of water-amide exchange rates using the phase-modulated CLEAN chemical EXchange (CLEANEX-PM) approach with a fast-HSQC (FHSQC) detection scheme. $J$ Biomol NMR 1998, 11:221-226.

14. Zhang $Y Z$ : Protein and peptide structure and interactions studied by hydrogen exchange and NMR. PA, USA: University of Pennsylvania; 1995.

15. Aste T, Weaire D: The Pursuit of Perfect Packing. New York: Taylor \& Francis; 22008.

16. Lyon LA, Meng ZY, Singh N, Sorrell CD, John AS: Thermoresponsive microgel-based materials. Chemical Society Reviews 2009, 38(4):865-874

17. Homouz D, Stagg L, Wittung-Stafshede P, Cheung MS: Macromolecular crowding modulates folding mechanism of $\alpha / \beta$ protein apoflavodoxin. Biophys J 2009, 96(2):671-680.

18. Ping $G H$, Yang GL, Yuan HM: Depletion force from macromolecular crowding enhances mechanical stability of protein molecules. Polymer 2006, 47(7):2564-2570.

19. Wagner G: A novel application of nuclear Overhauser enhancement (NOE) in proteins: Analysis of correlated events in the exchange of internal labile protons. Biochem Biophys Res Commun 1980, 97(2):614-620.

20. Neira JL, Itzhaki LS, Otzen DE, Davis B, Fersht AR: Hydrogen exchange in chymotrypsin inhibitor 2 probed by mutagenesis. J Mol Biol 1997, 270(1):99-110

21. Bai $Y$, Milne JS, Mayne L, Englander SW: Primary structure effects on peptide group hydrogen exchange. Proteins: Struct, Funct, Genet 1993, 17(1):75-86.

22. Chen XW, Chen SA, Wang JH: A pH-responsive poly $(\mathrm{N}$ isopropylacrylamide-co-acrylic acid) hydrogel for the selective isolation of hemoglobin from human blood. Analyst 2010, 135(7):1736-1741. 
23. Boyer JA, Lee AL: Monitoring aromatic picosecond to nanosecond dynamics in proteins via $\mathrm{C}-13$ relaxation: Expanding perturbation mapping of the rigidifying core mutation, V54A, in eglin c. Biochemistry 2008, 47(17):4876-4886

24. Vicky DN, Loria JP: The effects of cosolutes on protein dynamics: The reversal of denaturant-induced protein fluctuations by trimethylamine $\mathrm{N}$-oxide. Protein Sci 2007, 16(1):20-29.

25. Henzler-Wildman K, Kern D: Dynamic personalities of proteins. Nature 2007, 450(7172):964-972

26. Jyotica $B$, Ke $X$, Huan-Xiang Z: Nonadditive effects of mixed crowding on protein stability. Proteins: Struct, Funct, Bioinf 2009, 77(1):133-138.

27. Jones CD, Lyon LA: Synthesis and characterization of multiresponsive core-shell microgels. Macromolecules 2000, 33(22):8301-8306

28. Serpe MJ, Jones CD, Lyon LA: Layer-by-layer deposition of thermoresponsive microgel thin films. Langmuir 2003, 19(21):8759-8764.

29. Blackburn WH, Lyon LA: Size-controlled synthesis of monodisperse core/ shell nanogels. Colloid and Polymer Science 2008, 286(5):563-569.

30. Meng ZY, Smith MH, Lyon LA: Temperature-programmed synthesis of micron-sized multi-responsive microgels. Colloid and Polymer Science 2009, 287(3):277-285

31. Kay LE, Torchia DA, Bax A: Backbone dynamics of proteins as studied by ${ }^{15} \mathrm{~N}$ inverse detected heteronuclear NMR spectroscopy: Application to staphylococcal nuclease. Biochemistry 1989, 28(23):8972-8979.

32. Lee AL, Wand AJ: Assessing potential bias in the determination of rotational correlation times of proteins by NMR relaxation. J Biomol NMR 1999, 13(2):101-112.

doi:10.1186/2046-1682-4-13

Cite this article as: Miklos et al:: An upper limit for macromolecular crowding effects. BMC Biophysics 2011 4:13

\section{Submit your next manuscript to BioMed Central} and take full advantage of:

- Convenient online submission

- Thorough peer review

- No space constraints or color figure charges

- Immediate publication on acceptance

- Inclusion in PubMed, CAS, Scopus and Google Scholar

- Research which is freely available for redistribution

Submit your manuscript at www.biomedcentral.com/submit
Biomed Central 